\title{
Students' Perceptions of the Use of AI in a Writing Class
}

\author{
Dian Toar Y. G. Sumakul ${ }^{1 *}$, Fuad Abdul Hamied ${ }^{2}$, and Didi Sukyadi ${ }^{3}$ \\ ${ }^{1}$ Universitas Kristen Satya Wacana; \\ Ph.D. Candidate at Universitas Pendidikan Indonesia \\ ${ }^{2}$ Universitas Pendidikan Indonesia \\ ${ }^{3}$ Universitas Pendidikan Indonesia \\ *Corresponding author. Email: toar.sumakul@upi.edu
}

\begin{abstract}
With its current developments, Artificial Intelligence (AI) has started to influence how teachers teach and how students learn, including the ones in English as a Foreign Language (EFL) classrooms. However, there have been debates on whether AI could be beneficial to students' learning or not. One way to see this issue is from the perspectives of the students. Hence, this study aimed at investigating how students perceive the use of AI in their learning. The data was collected through semi-structured interviews with 8 EFL students in a university in Indonesia who had the experience with the use of an AI app in their writing class. The results showed that the students had positive perceptions towards the use of the AI app. The students enjoyed the learning, and the AI app helped the students in their writing. Moreover, this study also suggests that there are also several things to consider when integrating AI in writing classes.
\end{abstract}

\section{Keywords: Students’ Perceptions, Artificial Intelligence, EFL Classrooms, Writing}

\section{INTRODUCTION}

Artificial Intelligence (AI) is affecting every aspect of human life, including education. As AI offers automation, AI could affect the process of teaching and learning, bringing new challenges and demands for both teachers and students. In other words, AI could change how teachers teach and how learners learn. This also applies to language classrooms, EFL (English as a Foreign Language) classrooms in particular.

$\mathrm{AI}$ is getting more common in EFL classrooms, and one important element to consider when integrating this technology should be how students accept this technology. Users' acceptance has been proven as a key indicator in the success of technology integration to improve performance [6]. In the context of EFL classrooms, users here could refer to EFL students. When the students could accept the use of the technology, learning performance could be improved. One way to measure students' acceptance is to understand how they perceive the technology in their learning. In the context of EFL classrooms, many studies have shown the importance of students' perceptions in ICT technology integration, but only very few regarding AI technology.

As AI technology is starting to invade EFL classrooms and students' perceptions are important in technology integration, this study wanted to see how the EFL students perceive the utilisation of AI technology in their writing class in a university in Indonesia. For this purpose, this study employed the following research questions:

1. How do EFL students perceive the use of AI technology in their writing class?

2. What are the aspects EFL teachers need to consider when incorporating AI technology in a writing class?

\section{LITERATURE REVIEW 2.1. Artificial Intelligence in Language Learning}

There are many definitions offered for Artificial Intelligence (AI), but it could be simply defined as intelligent machines. The intelligence here refers to human intelligence. The intelligence here refers to human intelligence. Synthesising some previous definitions, Russel and Norvig [28] sum up that AI can be defined as machines that can think and act humanly and rationally. For example, nowadays we have AI that could drive a car, perform medical operations, show directions, give legal advice, and many others. Accordingly, in a language classroom, AI would perform the roles of a language teacher [3] [22]. For learners, AI could promote more personalised learning.

As AI brings the promise of personalised learning, many studies applaud the advantages that AI offers to language learning. Since its introduction to language 
classrooms in the $1980 \mathrm{~s}, \mathrm{AI}$ is able to provide feedback to students' grammar [3], engage students through written interactions [14], process students' language input [13], give more effective grammar feedback [23], assist students' errors in grammar [7], provide better learning experiences [16], conduct meaningful communications [18], help students gaining more confidence [11], increase students' motivation [12], and increase students' reading comprehension [2]. These findings suggest that AI offers a huge potential in language learning.

\subsection{The Importance of Students' Perceptions}

The technology might offer good promises, but how the users perceive it is as also significant. In the context of technology integration in language learning, as the users, students' perception is of great importance. From cognitive psychology, Marx [21] argue that learner's perceptions could affect the learning activities designs, teachers' classroom management for students' learning, and how students see themselves as successful learners. Moreover, Lizzio et al. [17] see the importance of students' perceptions using Biggs' [4] Presage-ProcessProduct (3P) model, where students' perceptions are framed in the first P as students' characteristics. These 3 Ps are suggested as the 3 vital factors for students' learning. However, they cannot be treated separately as they play a unified, integrated role. In relation to this, Astika and Sumakul [1] found that by relying on Process only would not guarantee students' success in EFL classrooms.

In general, students will use a technology if they think it is easy to use and beneficial to their learning. These are explained by the terms perceived usefulness and perceived ease of use in Davis' [6] Technology Acceptance Model (Figure 1). The model shows the interplay of some factors affecting the use of technology.

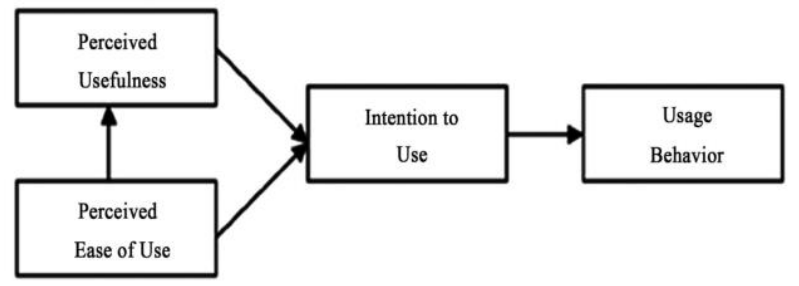

Figure 1 Technology Acceptance Model [6]

Perceived usefulness and perceived ease of use would influence the intention to use which would later affect usage behaviour; how a person would use technology. In other words, in the context of this study, how EFL students perceive a technology would affect their intention to use the technology and later how they use it in language learning.

In fact, studies on students' perceptions of technology integration in language classrooms are not new, and many came up with positive results. Among them, however, only a few looked at AI technology. For example, Haristiani [11] found that learners are interested in using chatbots because they could use chatbots anytime anywhere. She also observed that the students were more confident in their learning activities when they used chatbots compared to when they talked to human tutors. Similarly, Haryanto [12] also found that his EFL students were enthusiastic when they were introduced to AI in their learning. Another example, Bailey et al. [2] used story bots in their classrooms. The study revealed that the students believed that the AI helped them meet their L2 goals, relevant to their learning, and was easy to use.

\section{METHODOLOGY}

\subsection{Participants}

The participants of this study were eight EFL students in an English Language Education department at a university in Indonesia. They were introduced to an AI app in their writing class when they were assigned to write short stories.

The participants were part of a larger group for another study looking at their motivation while working with Artificial Intelligence. The group had completed a questionnaire to measure their motivation and the eight students were chosen to represent those with low, medium, and high levels of motivation. Initially, there were nine students contacted to participate in the interview, with three students represented each motivation level, but only eight replied and were committed to do the interview. Within the context of this study, which is about students' perceptions, the participants various motivation levels were also expected to enrich the findings on the their perceptions.

\subsection{Technology}

The AI used in this study was a free web-app called Plot Generator that can be accessed from https://www.plot-generator.org.uk/. This app offers the creation of a wide range of plots, such as movie scripts, opening lines, fairy tales, opening lines, and short stories (see Figure 2).

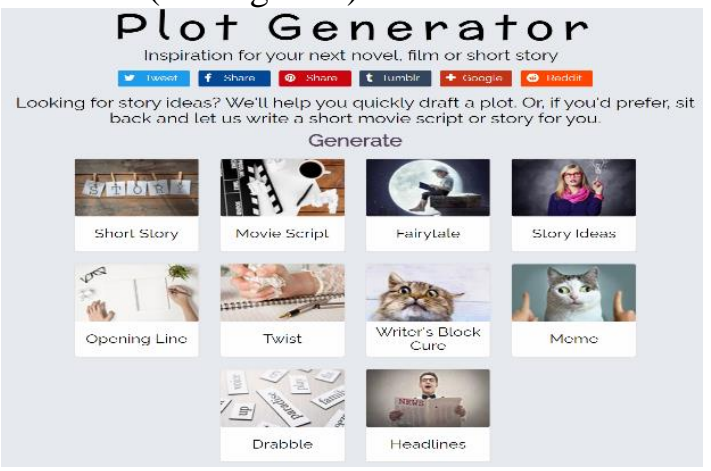

Figure 2 Plot Generator webpage 
In the writing class used in this study, the students were asked to choose Short Story. When they opened the Short Story section, the app would come up with a number of prompts or story elements for the app to use in making the short story (see Figure 3). Once all the prompts had been filled, students could click the button "write me a short story" and within seconds a short story would be written.

\subsection{Instrument}

The data for this study were the EFL students' perceptions of the use of Plot Generator in their writing class, and they were collected using interviews. The interviews were in forms of semi-structured interviews, where there were primary questions and follow-up questions based on the initial answers provided. In general, the primary questions were about their general opinions about the use of the AI in their writing class, how they used the AI, how the app helped them in their writing, the challenges they faced when using the app.

Some arguments support interviews as a sophisticated data collection tool.

One of them is interviews could reveal phenomena that cannot be seen with direct observations [19]

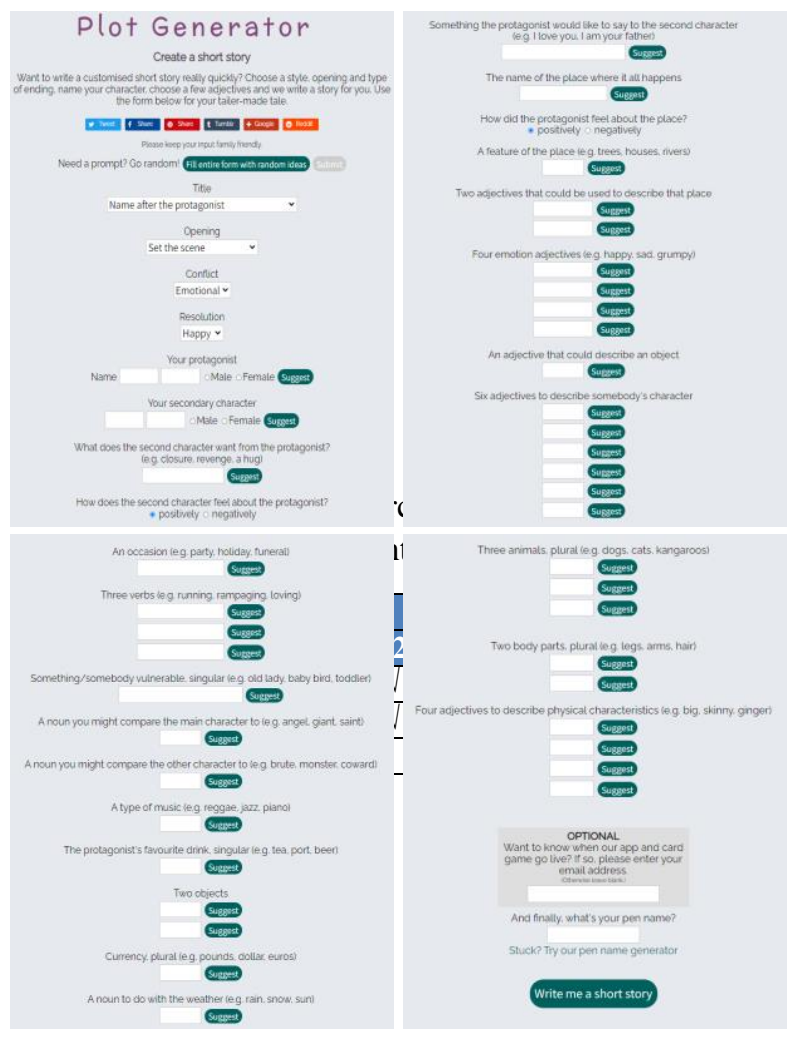

Figure 3 Prompts for short story generation

Moreover, the interviews were conducted using WhatsApp, a mobile instant messaging application. Kauffman and Peil [15] called this kind of interview as MIMI (Mobile Instant Messaging Interview). Interviews using instant messaging applications have been reported to have the several advantages, such flexibility in terms of time and place, cost efficiency, and richer data [15] [20] [24].

\subsection{Data Analysis}

The students' perceptions will be discussed from the perspectives of Davis' [6] model, focussing on two determinants: perceived ease of use and perceived usefulness. The latter, however, will be more elaborated since the study have more data on this matter.

\section{FINDINGS AND DISCUSSION}

This section will discuss how students perceive the use of the AI app, Plot Generator, in their writing class. Moreover, the pedagogical implications of the students' perceptions will also be elaborated.

\subsection{Students' Perceptions}

In general, all participants showed positive perceptions towards the use of Plot Generator in their writing class. Regarding perceived ease of use, all eight participants agreed that Plot Generator was easy to use. No report stating that they had technical problems when using the app. Participant 06 even emphasised that it was extremely easy, and Participant 04 explained that it was easy and fun. Davis [6] claims that when a technology is perceived to be easy, it is likely to be accepted by users. In the context of this paper, when this AI app is perceived to be easy to use, it would be likely that it would be accepted by the students in their learning.

In terms of perceived usefulness, all participants mentioned several things how Plot Generator was helpful in their writing class. In other words, the app assisted them when they did their writing assignments. The assistance can be categorised into 3 groups: theoretical concepts, writing process, and language. The distribution of the categories in each participant from the interview data is presented in Table 1.

The table indicates that all participants perceived that the Plot Generator app could help them during the writing process. Moreover, five participants reported that they were assisted with the language, particularly on grammar and vocabulary, and four participants claimed that they were helped in understanding the theoretical concepts needed in their writing.

\subsubsection{Theoretical Concepts}

A lesson usually consists of theoretical concepts for the students to understand in order to do the assignments. In this study, the students were learning about short stories when the app was integrated into their lesson. One example was given by Participant 02 who stated that she was helped by Plot Generator because she learned the elements required in a short story. Similarly, Participant 05 explained that they learned how to structure a short story. They were made understood that a short story could consist of an opening, conflict, and resolution. Another example about a theoretical concept learned by the participants is plot twist, as revealed by Participant 03. Participant 07 also shared that the app helped her to understand several genres in a short story. She said, "Apparently there are options when you write a short 
story. There are a number of genres. We could choose romance, horror, or other genres."

In conventional classroom settings, these theoretical concepts are usually explained by the teacher in a lecture. By incorporating this app, this teacher's role was handled by the app. However, the students were not helped to understand the concepts through a lecture, but learned them while working with the app.

\subsubsection{Writing Process}

The most important element in a writing class is when the students do the writing. This is when the students using the language, practice the writing skills. In this study, this was also the moment where the app reported to be useful. The first one was Plot Generator help the students by giving them ideas of what to write. Participant 01 said that they got the idea of how to develop the story. This was also reported by Participant 03, Participant 04, Participant 05, and Participant 08. Within the same sense, Participant 02 stated that the app helped her to find the theme for her story. Participant 03 emphasised that this app would be useful for beginner writers when there were writer's blocks. When they experienced difficulties on how to continue the story, this app could help.

In addition to providing ideas, there were some other helps provided by the app when the students were writing their stories. For example, Participant 03 said that the app helped her to choose a hook for the first sentence in a paragraph. Another example was from Participant 04, who stated that, "The app could guide me to write with different styles, with more variations." She also said that the app helped her to make her story novel-like. Participant 06 also mentioned about how the app helped him with the plot. This happened when he was confused about how the story should go. The last example came from Participant 07. She said that the app helped her to express her imagination in writing.

\subsubsection{Language}

One important element in writing is, of course, the language. This is the vehicle of the thoughts of the writer, where the writer's ideas are represented. The language here refers to the grammar and vocabulary the participants learned while using the app. From the 8 participants involved in this study, five participants reported they the app helped them learn grammar and/or vocabulary. For example, Participant 03 mentioned that she learned new words and phrases from the app. When asked to give examples, she gave the word "scuppered" and the phrase "curiosity kills the cat". Participant 07 also gave the words "selfish" and "silly" for examples. They never knew the words and phrases before and learned them while using the app in their writing. Still regarding vocabulary, Participant 04 mentioned, "This app helped me in recalling my vocabulary memory. So, the language I used in writing were becoming more diverse." Here, the participant did not learn new words, but the app helped her remember some words she already knew and used them in her writing. In another example, specifically to grammar, Participant 05 said that using the app made her grammar automatically correct so she could learn about grammar too. Regarding this, Participant 06 emphasised that if he had done it by himself, there would be so many grammatical mistakes in his writing. Participant 07 made clear that she could learn new knowledge regarding grammar and vocabulary from the app.

\subsection{Pedagogical Implications}

Perceptions are key determinants in technology acceptance [6]. In education, students' perceptions play an important role in determining the successful integration of a particular technology in the learning activities. As students are the subjects of the teaching and learning processes, when they perceive a particular technology could bring benefits to their learning, it is one key indicator that the technology could be applied in the classrooms. Therefore, within the context of this paper, based on the positive students' perceptions found in this study, it could be said that the Plot Generator app has the potential to be beneficial for EFL language learners. EFL students' positive perceptions towards the use of AI technology in their learning have also been reported in other studies [2] [11].

In addition to the positive perceptions, however, this study found that there were some drawbacks reported by the participants in relation to the sentences produced by the app. For example, Participant 06 mentioned that some parts of the story were unwanted. These made the story incoherent (Participant 02) and weird (Participant 05). Participant 02 further explained that the app just changed the words, not the story. Correspondingly, Participant 04 found that the patterns of the story were actually the same. These unnatural language productions have also been observed in other studies looking at various AI apps [5] [8] [9] [26].

Furthermore, although not directly related to writing, the interview data also revealed that Plot Generator could also help building students' soft skills. For example, this app could promote creativity and imagination. This was suggested by Participant 04 and 07 . By playing with the words inputted in the initial prompts, students could play with the words and try out different results. Moreover, when later asked to edit the story generated by the app, students could come up with different ideas on how to change and redecorate the story. This is also where critical thinking skills stepped in. Particularly, with the unnatural sentences and incoherent sections produced by the app discussed earlier, the students were then faced with problems they need to solve. In addition to creativity and critical thinking skills, students were also situated to practice their communication and collaboration skills when they were asked by the teacher to work in groups to edit the story. Participant 01,04 , and 05 reported that there were intense discussions and even debates in their groups. In fact, these communication and collaboration skills were not directly related to the characteristics of the AI app, but more to how the teacher designed the learning activities. 
It is not about the technology, but more importantly the pedagogy. This could be viewed from two perspectives: the teacher and the technology. From the teacher's angle, this could be translated as what more important is how the technology can be utilised to enhance students' learning. However, this could sometimes cause problems due to teachers limited pedagogical competence [29] [30]. From the other angle, Rieland [27] suggests that the problems may lie in the pedagogical design of the technology in question. This weak connection to theoretical pedagogical perspectives is one of the significant issues in the applications of AI technology in education [31]. Regarding the linguistic elements of an AI app, Pace-Sigge [25] suggests that linguists should be more involved in the development of AI technology. In the context of language teaching and learning, to have good links between the technology and its pedagogical application, this study would also suggest that language teachers should be of great importance as well.

In short, teachers' pedagogical competence is the key to successful AI technology integration in EFL classrooms. As Goodwin [10] suggests, machines only help in writing, humans are the main actors. In the context of this paper, AI is just a tool; teachers are still the determining factor.

\section{CONCLUSION}

This study found that the EFL learners who participated in this study showed positive perceptions towards the use of AI technology in their writing class. They reported that the AI used could help them understand the theoretical concepts, assist them during the writing process, and help them learn the grammar and vocabulary items in their writing. With these positive perceptions, this study suggests that AI technology could be beneficial to EFL students. However, another significant element to consider is teachers' technological competence. How teachers design the learning activities incorporating AI technology would further determine the success of the lesson.

AI technology integration in EFL classrooms is relatively a new topic in ELT. Although there have been some studies looking at this issue, there are still more to elaborate on. This study has presented a small contribution in this matter, particularly regarding the use of AI in a writing class. Nevertheless, more studies involving more data and more contexts are needed to have a better understanding of this issue.

\section{AUTHORS' CONTRIBUTIONS}

The $1^{\text {st }}$ author was responsible for the data collection. All authors, however, had equal contributions during the writing process of the paper.

\section{ACKNOWLEDGMENTS}

The authors would like to express their gratitude to the students participating in this study.

\section{REFERENCES}

[1] Astika, G., \& Sumakul, D. T. (2020). Students' profiles through learning approaches using Biggs' Study Process Questionnaire. ELTR Journal, 4(1), 36-42.

[2] Bailey, D., Southam, A., \& Costley, J. (2021). Digital storytelling with chatbots: Mapping L2 participation and perception patterns. Interactive Technology and Smart Education.

[3] Bailin, A. (1987). Artificial intelligence and computer-assisted language instruction: A perspective. CALICO Journal, 5(3), 25-45. https://doi.org/10.1558/cj.v5i3.25-45

[4] Biggs, J. B. (1989). Approaches to the enhancement of tertiary teaching. Higher education research and development, 8(1), 7-25.

[5] Coniam, D. (2014). The linguistic accuracy of chatbots: usability from an ESL perspective. Text \& Talk, 34(5), 545-567.

[6] Davis, F. D. (1989). Perceived Usefulness, Perceived Ease of Use, and User Acceptance of Information Technology. MIS Quarterly, 13(3), 319-340. https://doi.org/10.5962/bhl.title.33621

[7] Dodigovic, M. (2007). Artificial intelligence and second language learning: An efficient approach to error remediation. Language Awareness, 16(2), 99113. https://doi.org/10.2167/la416.0

[8] Fibriana, I., Ardini, S. N., \& Affini, L. N. (2021). Google Translate and its role in academic writing for university students. Journal Of Advanced English Studies, 4(1), 26-33.

[9] Gallacher, A., Thompson, A., \& Howarth, M. (2018). "My robot is an idiot!"-Students' perceptions of AI in the L2 classroom. Future-proof CALL: language learning as exploration and encounters-short papers from EUROCALL 2018 , 70.

[10] Goodwin, R. (2016, June 9). Adventures in narrated reality. Medium. https://medium.com/artists-andmachine-intelligence/adventures-in-narratedreality-6516ff395ba3

[11] Haristiani, N. (2019, November). Artificial Intelligence (AI) chatbot as language learning medium: An inquiry. Journal of Physics: Conference Series, 1387(1). IOP Publishing.

[12] Haryanto, E. (2019). Students' attitudes towards the use of Artificial Intelligence Siri in EFL learning at one public university. International Seminar and Annual Meeting BKS-PTN Wilayah Barat, 190195.

[13] Holland, V. M., Maisano, R., Alderks, C., \& Martin, J. (1993). Parsers in tutors: What are they good for? CALICO Journal, 11(1), 28-46. https://doi.org/10.1558/cj.v11i1.28-46

[14] Jehle, F. (1987). A free-form dialog program in Spanish. CALICO Journal, 5(2), 11-22.

[15] Kaufmann, K., \& Peil, C. (2020). The mobile instant messaging interview (MIMI): Using WhatsApp to enhance self-reporting and explore media usage in situ. Mobile Media and 
Communication, $\quad 8(2), \quad 229-246$. https://doi.org/10.1177/2050157919852392

[16] Köse, U., \& Arslan, A. (2015). E-Learning experience with artificial intelligence supported software: An international application on english language courses. GLOKALde, 1(3), 61-75.

[17] Lizzio, A., Wilson, K., \& Simons, R. (2002). University students' perceptions of the learning environment and academic outcomes: implications for theory and practice. Studies in Higher education, 27(1), 27-52.

[18] Lu, X. (2018). Natural Language Processing and Intelligent Computer-Assisted Language Learning (ICALL). The TESOL Encyclopedia of English Language Teaching, 1-6. https://doi.org/10.1002/9781118784235.eelt0422

[19] Mackey, A., \& Gass, S. (2005). Second language research: Methodology and design. Mahwah, NJ: Lawrence Erlbaum Associates

[20] Maeng, W., Ahn, H., Yoon, J., \& Lee, J. (2016). Can Mobile Instant Messaging $\mathrm{Be}$ a Useful Interviewing Tool? A Comparative Analysis of Phone Use, Instant Messaging, and Mobile Instant Messaging. HCI Korea 2016, January 2016, 45-49. https://doi.org/10.17210/hcik.2016.01.45

[21] Marx, R. W. (1983). Student perception in classrooms. Educational Psychologist, 18(3), 145164.

[22] Matthews, C. (1993). Grammar frameworks in intelligent call. CALICO Journal, 11(1), 5-27. https://doi.org/10.1558/cj.v11i1.5-27

[23] Nagata, N. (1996). Computer vs. workbook instruction in second language acquisition. CALICO Journal, 14(1), 53-75.

[24] Opdenakker, R. (2006). Advantages and Disadvantages of Four Interview Techniques in Qualitative Research. Forum Qualitative Sozialforschung / Forum: Qualitative Social Research, 7(4), Art. 11. http://nbnresolving.de/urn:nbn:de:0114-fqs0604118

[25] Pace-Sigge, M. (2018). Spreading activation, lexical priming and the semantic web: early psycholinguistic theories, corpus linguistics and AI applications. Springer.

[26] Pace-Sigge, M. \& Sumakul, D. T. (2021). What teaching an algorithm teaches when teaching students how to write academic texts (Manuscript submitted for publication).

[27] Rieland, R. (2017). Is artificial intelligence the key to personalized education? Smithsonian Magazine. https://www.smithsonianmag.com/innovation/artifi cial-intelligence-key-personalized-education180963172/

[28] Russel, S. J., \& Norvig, P. (2016). Artificial intelligence: A modern approach (3rd ed.). Essex: Pearson.

[29] Sumakul, D. T. (2019). When robots enter the classrooms: Implications for teachers. In $E$ proceeding of the international conference on embedding artificial intelligence (AI) in education policy and practice for Southeast Asia, 42-48. SEAMOLEC.

https://www.researchgate.net/publication/3386605 31_When_robots_enter_the_classrooms_Implicati ons_for_teachers

[30] Sumakul, D. T., Hamied, F. A., \& Sukyadi, D. (2021). Artificial intelligence in EFL classrooms: Friend or foe? (Manuscript submitted for publication).

[31] Zawacki-Richter, O., Marín, V., Bond, M., \& Gouverneur, F. (2019). Systematic review of research on artificial intelligence applications in higher education-where are the educators? International Journal of Educational Technology in Higher Education. https://doi.org/10.1186/s41239019-0171-0 